\title{
Musical Improvisation: Art, Education, and Society
}

\author{
Edited by Gabriel Solis and Bruno Nettl
}

Urbana and Chicago: University of Illinois Press, 2009

ISBN: 978-0-252-07654-1

357 pages

\section{Reviewed by Stephanie Khoury, McGill University}

Musical Improvisation: Art, Education, and Society, edited by Gabriel Solis and Bruno Nettl, is an important addition to the body of literature on improvisation. Including work from nineteen scholars, the book will surely further the growing dialogue about improvisation in the fields of musicology, education, and ethnomusicology, among others. In the book's introduction, improvisation is broadly defined as "the practice of making compositional decisions in the moment of performance" (1). However, the problems inherent in any attempt to define improvisation in such simplistic terms are readily exposed and challenged throughout the text. This volume presents readers with a number of contexts within which to explore the many processes of improvisation: African balafon music, Slavic folk culture, Indonesian Koranic cantillation, Persian Classical music, modern dance, jazz, and Western classical music.

Ethnomusicologists Solis and Nettl constitute a formidable team as editors and contributors. Nettl, who is widely held as a leading scholar in his field, is the author of the classic introduction to the field of ethnomusicology, The Study of Ethnomusicology: 31 Issues and Concepts. In many ways, the current volume serves as a successor to Nettl's previous collection of essays on the topic of improvisation, In the Course of Performance, published in 1998. Solis is a specialist in African-American music and is the author of Monk's Music: Thelonious Monk and Jazz History in the Making. His insightful introduction to the volume provides a thorough foundation for understanding the current state of improvisation studies in academia. Citing the work of Lydia Goehr, The Imaginary Museum of Musical Works, he problematizes the "intellectual cul-de-sac" (9) that has been created by exclusive focus on the conventional canon within musicology. Citing the lack of proposed solutions to this problem, Solis suggests that scholars commit to the study of improvisation and creativity in music-making, including all of the choices that performers make in the moment, from smaller elements such as phrasing and timing, to larger melodic and harmonic composition. Doing this, he proposes, "might lead us not to forsake the study of works and the various canons of the music we study, but to put such study in its place, as one portion of larger, living musical traditions" (9).

The essays in the present volume originated at a conference held at the University of Illinois Urbana in 2004 . They are organized into three sections roughly focused on ethnomusicology, education, and musicology or music theory. The division into three sections seems arbitrary at times, and I found myself questioning the placement of many essays. However, the diversity and complexity with which improvisation is approached demands the reader to step outside the boundaries that currently divide the distinct fields and view improvisation as a shared activity which connects various areas of musical study.

The first section, entitled "Society," offers primarily ethnomusicological perspectives and deals with social and political processes in relation to improvisation. Ethnomusicologist Ingrid Monson begins this section with an extended essay titled "Jazz as Political and Musical Practice." In an attempt to relate social and musical worlds, Monson calls upon ethnomusicologists to increase the scope of their subject matter, from a study of non-Western musics, to a discipline that includes popular musics, globalization, recording technologies, politics, identity, and gender. She focuses on the processes and practices with relation to social categories, and connects jazz and West African balafon music via practice theory, dealing extensively with race. For an opening chapter in a book about improvisation, the content appears to be less about improvisation than one would expect. However, Monson's perspective situates multiple themes and pertinent questions that are explored further throughout the book.

In "John Cage and Improvisation: an Unresolved Relationship," Sabine M. Feisst presents a thorough synopsis of Cage's evolving aesthetic principles and the evolution of his relationship with improvisation. Cage displayed an adversity towards improvisation throughout most of his career, and although he eventually incorporated improvisation into his compositions, it was with the aim of achieving the completely "unforeseen" and was clearly nothing like what jazz musicians or other improvising music cultures practice.

Thomas Turino closes the first section with an article dealing with "improvisation in relation to the goals and ethics of participatory music." This is a particularly interesting and relevant article, which distinguishes between formulaic playing and "true" improvisation. Turino discusses the mental state of flow and C. S. Peirce's philosophical categories 
of "Firstness, Secondness, and Thirdness" with regard to improvisation, shedding some light on processes that can appear mysterious and impossible to discern. Incorporating these mental states into performances has complex implications, which Turino insightfully addresses.

Educator and ethnomusicologist Patricia Shehan Campbell appropriately begins the second section of the book with a compelling article about learning improvisation and improvising in order to learn music. She raises important concerns dealing with music education in the academic setting of the United States and discusses the potential role of improvisation in providing students with a more comprehensive sense of music. Campbell also explores the role of musical improvisation in learning about oneself, other people, and the world beyond music. She draws numerous insights from improvisers across a spectrum of musical styles, helping the reader to understand, from individual perspectives, the complexity and richness in the process of improvisation. Campbell examines the beliefs of theorists who claim that "concepts and skills are best learned when the knowledge is situated, or constructed from active experiences" (133). She offers educational strategies including the pedagogical techniques inherent in the Dalcroze method. Her belief in the simultaneity of conscious and unconscious acts and the "liaison between will and reaction, imagination, analysis, realization, and creation" (135) has enormous significance for pedagogy that seeks to advance the construction of more holistically trained musicians. Campbell makes a compelling critique against educators who neglect improvisation, and she presents a progressive stance towards the creation of an expansive pedagogy of improvisation.

The next two equally persuasive articles come from the viewpoints of not only scholars, but also artists, as both Robert Levin (piano) and Charlotte Mattax Moersch (harpsichord) are renowned performers on their respective instruments. Moersch gives a thorough analysis of keyboard improvisation in the Baroque era, full of detailed and informative reproductions from composers/improvisers of the period. Levin presents a concise yet thorough look at Mozart the improviser, reminding us that in the musical environment of the eighteenth century, "all composers were performers, and virtually all performers composed" (143). In the twentieth century, musicians have aspired to "piously observe the written testament of the composer," yet after examining the realities of Mozart's extensive use of improvisation, "it must be said that many of today's performances contain passages executed in a manner Mozart would have considered unacceptably incomplete" $(144,147)$. Levin sheds light on the fact that today's performers are shaped by their preparation for competitions and recordings, and are therefore afraid to risk consistency and accuracy. Levin, himself willing to challenge the conventional methods of performance by incorporating improvisation in his own concerts, suggests that there is a wealth of tools for learning the improvisatory style of the Classical period and of Mozart's music specifically. Above all, he reminds us that perseverance and practice will assist the performer in bringing back spontaneity into "the humdrum conventions that have made much of classical music into something to relax to" (148).

John P. Murphy writes one of the surprisingly few articles in the book dealing exclusively with improvisation in the jazz tradition: in this case, the arguments for and against "school jazz." Murphy, as an alumnus of the University of North Texas Jazz Department, offers an insider perspective into formal improvisation studies at the university level. In a related piece, Bruno Nettl provides another personal account of learning a practice that is inherently improvisational: Persian classical music. Nettl has coined the term PoD (points of departure) to describe musical phenomena such as motifs and sequences which must be acquired before one may improvise within a certain style, a common thread among Persian Classical music and other practices such as jazz and Hindustani music (185).

In a similar vein, Stephen Slawek contributes "Hindustani Sitar and Jazz Guitar Music: A Foray into Comparative Improvology." Slawek is a renowned performer of sitar and a disciple of Pandit Ravi Shankar. He gives an interesting account of learning to improvise in India and draws comparisons with the Italian American Jazz guitar culture of South Philadelphia, where he took guitar lessons with Joe Sgro. Slawek refers to "the codification of the materials of improvisation" and provides informative musical diagrams from Sgro and others (205). As a guitarist, I particularly enjoyed this chapter, which served as a fascinating account of the methods and environments of these two distinct and yet kindred "families" of learning.

Last in this section, John Toenjes contributes an enlightening discussion of his role as a contemporary improvising musician in the modern dance class, an infrequently addressed venue of improvisatory music. In this context, musicians "attempt to inspire artistry in the dancers through emotional intent and intriguing musical ideas," becoming co-experimenters with instructors and serving together as facilitators for the dancers' artistry. Toenjes explores the different aspects of this process and emphasizes the important concept of the marriage of music and movement.

Ethnomusicologist Stephen Blum opens up the third section of the book, "Creation," by approaching the complex question of terminology both in the broader sense of composition, performance, and improvisation and in the more 
specialized sense of alternatives to the term "improvisation," such as "aleatoric music," "open form," and "oral composition." He continues by dissecting the phases of the creative process and delineating the necessary conditions for extemporary music. He details the advances in the understanding of improvisatory practices in the twentieth century from an ethnomusicological perspective.

Lawrence Gushee presents an interesting lexicographic discussion of the terms used in early jazz to describe improvisation, such as "fake", "interpolate" and, "playing hot." He draws from jazz musicians, composers, and writers of the period who used such terms to designate nuances and particular practices corresponding to the development of jazz through the 1920 s and 30s.

Rounding out the volume, Robert Hatten, William Kinderman, and Nicholas Temperley each deal with the relationship of improvisation to composition and performance in Western classical music. Temperley discusses the improvised nature of Chopin preludes, Hatten deals with the canonic works of Chopin and Schuman, and Kinderman challenges "The Beethoven Paradigm." All three of these texts are engaging musicological studies that challenge the absence of improvisation in modern classical performance tradition.

In conclusion, this book speaks across disciplinary boundaries by including a wide variety of scholars from multiple traditions: historical musicology, music education, ethnomusicology, and music performance. Each chapter offers a unique and valuable perspective and together they create such depth that we may entertain Solis's view for the future, namely that "the study of improvisation will ultimately melt into the basic paradigms of musical study, so that there may no longer be a rationale for studying it as distinct from the rest of music making" (9). I would have also liked to see a chapter focusing specifically on the subject of gender and improvisation, considering the wealth of material currently being published in this field, and I feel that the long-standing practice of improvisation on the organ, which is the only instrument that continues to practice improvisation in western classical music, deserves attention. However, the diverse range of essays will undoubtedly provide scholars with an expanded palette of material by which to extend the field of improvisation studies and provide valuable discourse for employing music and improvisation as metaphors for life, society, and culture.

\section{Works Cited}

Goehr, Lydia. The Imaginary Museum of Musical Works: An Essay in the Philosophy of Music. Toronto: Oxford UP, 1992. Print.

Nettl, Bruno, and Melinda Russell, eds. In the Course of Performance: Studies in the World of Musical Improvisation. Chicago: U of Chicago P, 1998. Print.

Solis, Gabriel, and Bruno Nettl. Musical Improvisation: Art, Education, and Society. Urbana: U of Illinois P, 2009. Print. 